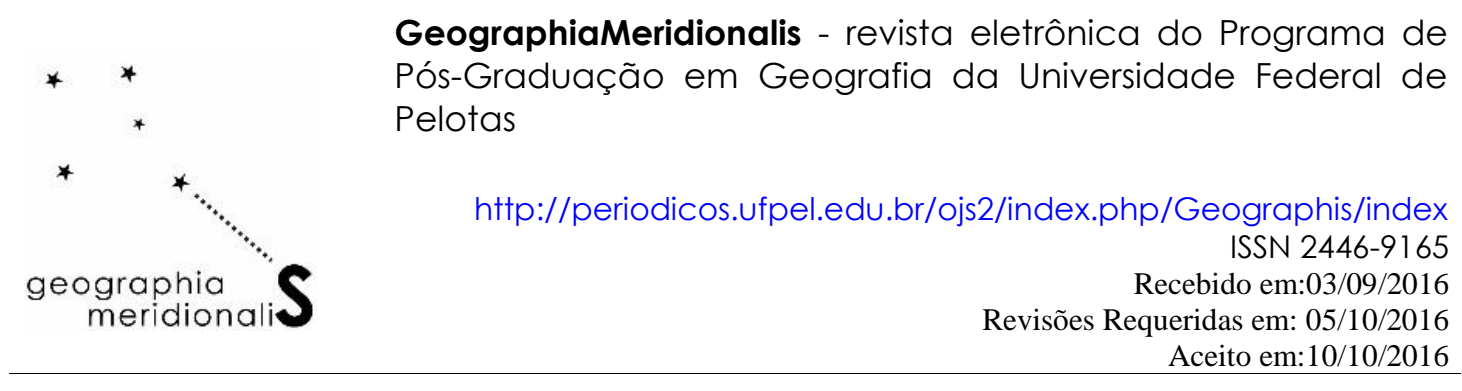

O COSMOS DE ALEXANDER VON HUMBOLDT

Marquessuel Dantas de Souza
Faculdade de São Paulo. São Paulo-SP
Graduado em Geografia
Membro do Grupo de Pesquisa Geografia, Literatura e Arte (Geoliterart) da USP
marquessuelgf@ hotmail.com

HUMBOLDT, Alexandre von. In: bossert, A. Histoire de la Littérature Allemand. Le Romantisme. Paris: Hachette et Cie, pp. 844-848, 1901, 1120p. $\mathrm{t}^{1} .1904$.

\title{
Apresentação
}

O presente texto volta sua atenção para uma breve abordagem sobre a obra Cosmos de Humboldt. Em todo ocaso, se nos apresente como mais uma contribuição à história desse pensador singular do século XIX. Ademais, é um estudo referente aos ensinamentos humboldtianos em relação à Geografia científica. Com efeito, traduz nitidamente o grau de importância deste sábio alemão para com a cultura mundial.

Humboldt fora o Aristóteles de seu tempo. Produziu muito e deixou um legado fixamente constituído. Sua obra Cosmos representa o amadurecimento das experiências vividas por ele. Nesta obra o mesmo expõe todo um conhecimento coerente e decifra, por assim dizer, aquilo que até então não havia sito descoberto. Obra em que se pode dizer: teve uma gestação de quase meio século. Veio à luz depois de muito esforço cuidadosamente trabalhado em seus pormenores.

O Cosmos de Humboldt simboliza o nascimento de um novo olhar sobre o mundo e a natureza como um todo (a existência). Representa a obra mais bem elaborada da geografia tradicional-moderna, antes do surgimento da geografia da segunda metade do século XIX. Obra de referência singular que certamente influenciou autores como Friedrich Ratzel e

\footnotetext{
1 Tradução de Marquessuel Dantas de Souza. Estudante do Grupo de Pesquisa Geografia, Literatura e Arte (Geoliterart) da USP.
} 
Paul Vidal de la Blache, por exemplo, assim como outros. Obra ainda hoje estudada como de cunho poético (literário), apesar de suas análises físicas e humanas ali contidas (científicas). No Brasil, Antonio Carlos Vitte (Unicamp) em coordenação com seus colaboradores (grupo de pesquisadores) buscam desvendar cada vez mais a obra de Humboldt. Não obstante, muito já fora desenvolvido (teses, dissertações, monografias, artigos entre outros) seguindo a linha de pensamento elaborada por Vitte (elementos da origem da geografia física científica); além disso, é notório acrescentar os trabalhos de Lúcia Riccota, dos mesmos encontra-se Natureza, Ciência e Estética em Alexander von Humboldt, Mauad, 2003. Entre outros trabalhos da mesma natureza.

O texto aqui exposto fora extraído de uma obra monumental sobre a História da Literatura Alemã, de Adolphe Bossert, publicada em 1901. Constitui o capítulo I da terceira seção (a ciência e a história) do sétimo período (O Romantismo: após o fim do século dezoito até a revolução de 1848), conforme a organização da obra.

Com efeito, é neste sentido que, grosso modo, o texto a seguir busca mostrar o real valor cultural (epistemológico: filosófico, artístico e científico) de Humboldt e sua obra. Humboldt, a enciclopédia viva de sua época.

\section{O Cosmos de Alexander von Humbolt}

Os dois irmãos Wilhelm e Alexander von Humboldt tem uma característica comum, uma tendência a universalidade que não lhes impedem de se livrar dos estudos muito especiais. Seus próprios domínios foram diferentes. Aquele de Alexander é a ciência da natureza, na mais vasta acepção desta palavra. Ele viu a natureza como uma grande unidade que contém em seu seio forças múltiplas que se combinam e se harmonizam, mesmo que elas pareçam se combater, e que todas visam ao mesmo objetivo: à multiplicação da vida. Ele, de bom grado, personificou [a natureza] como nos tempos antigos ${ }^{2}$. Ela atrai, lhe cativa por todas as espécies de leis, pela curiosidade do sábio, pela abertura que se dá ao espírito, mesmo pela calma e tranquilidade que ela traz ao coração. Não é sem razão que seu Cosmos se abre por um capítulo das considerações sobre os diferentes graus de prazer oferecidos pelo aspecto da natureza e do estudo de suas leis. "O simples contato do

\footnotetext{
${ }^{2}$ Ele ensaiou uma personificação deste gênero em um episódio dos Quadros da Natureza, inserido primeiro nas Horas [Periódico] de Schiller de 1795: a Força Vital ou o Gênio Ródio. Mas a personificação é vaga, como o objeto que era a personificar. Acréscimo do tradutor de alguns colchetes e termos anexos ao longo do texto e em algumas notas.
} 
homem com a natureza" - diz ele em uma das primeiras páginas -, "esta influência do ar considerável, ou, como dizem outras línguas com uma expressão mais bela, ao ar livre, tem um poder calmante; ele adoça a dor e apazigua as paixões. Estes benefícios, o homem recebe por toda parte, seja qualquer zona que o mesmo habite ou qualquer que seja o grau de cultura intelectual ao qual se educou. Essas impressões que assinalamos aqui são solenes, elas mantêm pressentimentos de ordem e de leis, que nascem, para nossa ignorância, do simples contato com a natureza; mantém-lhes do contraste que oferecem os limites estreitos de nosso ser com esta imagem do infinito que se revela por toda parte, na curva estelar do céu, num plano que se estende à parte da vista, no horizonte nevoento do oceano" (HUMBOLDT, 1846, p. 04) ${ }^{3}$. Entrar na intimidade da natureza foi o objeto de toda sua via, o intento constante e único dos estudos variados que ele empreendeu sucessivamente ${ }^{4}$.

Nascido em Potsdam em 1769, ele segue seu irmão, após um ano, para a universidade de Göttingen. Lá conheceu Forster ${ }^{5}$, que voltara de uma viagem ao redor do mundo, e percorreu com ele os Países Baixos (Holanda) e a região do Reno. Desde então o pensamento de uma grande exploração longínqua eleva-se em seu espírito. Ele se prepara para excursões geológicas e botânicas na Suíça, em Tirol e na Alta Itália; segue durante um ano os cursos da Escola de minas de Freiberg, onde teve por mestre Werner ${ }^{6}$; orientase em todos os domínios das ciências naturais. Enfim, estuda línguas: francês, inglês, espanhol.

Alexander von Humboldt é o tipo de explorador, não apenas pela maneira de viajar, mas também pela arte da organização. Em 1797, foi à Paris para procurar os melhores instrumentos meteorológicos e astronômicos; reencontra seu irmão Wilhelm e traça

\footnotetext{
${ }^{3}$ Cosmos: ensaio de uma descrição física do mundo, traduzido por Faye e Galuski; Paris, 1855-1859. Este primeiro capítulo fora escrito em francês pela mão do próprio Humboldt. Ele sempre se ocupou, especialmente, das edições francesas de suas obras; algumas vezes acrescentou trechos inéditos. Nota do autor.

- A referência da paginação do trecho citado (HUMBOLDT, 1846, p. 04) fora extraído de uma edição de 1846, na qual a consultamos. HUMBOLDT, Alexandre de. Cosmos: essai d'une description physique du monde. (Traduction de M. H. Faye). Primière partie (Vol. 1). Milan: Charles Turati, 1846. 436p. Acréscimo do tradutor.

${ }^{4}$ Todos os grifos no presente texto (corpo e notas) são conforme o original. Exceto algumas alterações especificadas quando necessário.

${ }^{5}$ George Forster (1754-1794) foi um naturalista e etnólogo alemão. - Ressalta-se que em alguns textos a inscrição de seu nome aparece como Förster. (N. T.).

${ }^{6}$ Abraham Gottlob Werner (1749-1817) foi um geólogo e mineralogista alemão. Como exposto no texto, um de seus estudantes (alunos) fora Humboldt. (N. T.).
} 
relações com Arago, Gay-Lussac, Berthollet. Dois anos depois, embarca com o botânico Aimé Bonpland para a América Central. Eles exploram em conjunto a bacia do Orenoco, as Cordilheiras, a Ilha de Cuba, o México, regressando pelos Estados Unidos. Alexander von Humboldt fixa sua residência em Paris para coordenar e publicar os resultados de sua viagem $^{7}$. Ele escreveu em alemão os Quadros da Natureza, que são como o lado pitoresco de sua relação ${ }^{8}$. Em 1829 ele empreende, a convite do governo russo, uma viagem de exploração nas regiões dos Urais e dos Altai e nas estepes do Mar Cáspio, e pôde assim, completar no Norte as observações feitas nos trópicos ${ }^{9}$. Todavia, seus desejos não foram satisfeitos: ele queria visitar ainda os planaltos do Tibet (Tibete) e do vale da Caxemira, onde a ciência situa, então, como o berço da humanidade. De 1838 a 1848, ele viveu alternadamente em Paris e na Alemanha. Em suma, cede às instâncias do rei Friedrich Wilhelm III (Frederico Guilherme) e se fixa em Berlin, onde morreu cheio de vida e de honras em 1859.

É em 1845 que começa a publicação de seu Cosmos, cujo pensamento o ocupou, diz ele, depois de meio século; o último volume apareceu em $1858^{10}$. Neste intervalo, ele não cessou de endereçar memórias à Academia de Ciências de Berlin e aos acadêmicos estrangeiros e continuou mantendo relações epistolares não só com todos os eruditos da Europa, mas ainda com todas as pessoas que lhe pediam um conselho ou um apoio. "Sucumbo" - escreveu dois meses antes de sua morte -, "sob o peso de uma

\footnotetext{
${ }^{7}$ A grande edição francesa de Viagem às regiões equinociais do novo continente compreende seis partes (relação histórica; zoologia e anatomia comparada; Ensaio político sobre o reino da Nova Espanha; astronomia, etc.; geologia; botânica), cuja publicação se prolongou até 1832. - Uma tradução alemã, muito defeituosa, da Relação histórica apareceu de 1815 a 1829, em Stuttgart, em seis volumes. Uma versão abreviada foi feita, com a autorização do autor, por H. Hauff: Reise in die AEquinoctial-Gegenden des neuen Continents, 4 vol., Stuttgart, 1859-1860.

${ }^{8}$ Ansichten der Natur, 2 vol., Stuttgart e Tübingen, 1808; $2^{\mathrm{a}}$ ed.. 1826; $3^{\mathrm{a}}$ ed., 1849. A obra era atualiza a cada edição. As duas primeiras edições foram traduzidas por Eyriès, a terceira por Galuski. A tradução francesa de 1826 contém trechos que não figuram no original.

${ }^{9}$ Os dados desta viagem foram organizados em alemão pelo mineralogista Gustave Rose: Reise nach dem Ural, dem altai und dem Kaspischen Meer, 2 vo., Berlin, 1837-1842. - (Viagem aos Urais, Altai e ao Mar Cáspio).

10 Cosmos, Entwurf einer physisch Weltbeschreibung, 4 vol., Stuttgart e Tübingen, 1845-1858. Literalmente, Cosmos: projeto de uma descrição física do mundo. Em realidade, HUMBOLDT, Alexander von. Kosmos: entwurf einer physischen weltbesschreibung. 5 vol. Stuttgart und Tübingen: J. G. Cotta'ischer Verlag, 1845-1862. O quinto volume publicado postumamente. Acréscimo do tradutor.
} 
correspondência de oitocentos a duas mil cartas e grandes quantidades por ano" $(\text { HUMBOLDT, 1865, p. XXIX) })^{11}$.

Humboldt pertence, antes de tudo, à Ciência; ele se ocupou de física, de mineralogia, de geologia, de botânica, de zoologia; suas experiências sobre o magnetismo terrestre fizeram época; a geografia das plantas e sua criação. Entretanto, ele sempre procurou dar a seu pensamento uma expressão literária. Escreveu facilmente em francês e em alemão; sua atenção era dirigida, antes, mais sobre o detalhe que sobre o conjunto; ele não compunha. Arago lhe disse um dia, com a franqueza de um amigo: "Humboldt, você não sabe como se faz um livro; você escreve sem fim, mas isto não é um livro, é um retrato sem moldura" (ARAGO, citado por DE LA ROQUETE, 1860, p. 251) ${ }^{12}$. Este julgamento, em sua rudeza familiar, encerra um fundo de verdade. Os Quadros da Natureza, a obra mais literária de Humboldt, oferece páginas características; surpreendem pela novidade dos sujeitos; mas o lado pitoresco é alargado e obscurecido/ofuscado pelo detalhe geográfico. O Cosmos é um quadro da natureza inorgânica em suas grandes divisões, os espaços celestes e o globo terrestre; ela se detém no limite onde começa os seres organizados. A obra está dividida em várias partes, que se complementam uma a outra, mas que não se ligam diretamente; termina por uma nota sobre a presença de obsidiana ${ }^{13}$ nas rochas vulcânicas. Evidentemente, Humboldt teve, sobre a composição literária, as idéias de um sábio que, completamente penetrado da grandeza de seu sujeito, não pretendeu ser claro, exato e completo. Ele vai dizer que seu método é aquele da observação rigorosa e aprofundada, não proibindo de maneira nenhuma as comparações e as generalizações, mas é inimigo da hipótese ativa e da abstração vazia.

Esta é a última característica que Alexander von Humboldt exerceu, uma influência salutar sobre a literatura e sobre a filosofia. Aos conceitos abstratos, tirados da imaginação especulativa, opôs a generalização científica, fundada sobre a experiência. "O princípio fundamental de meu livro", diz ele, "tal qual eu o desenvolvi a mais de vinte anos, nas lições professadas em francês e em alemão, em Paris e em Berlin, é a tendência constante

\footnotetext{
${ }^{11}$ HUMBOLDT, Alexandre de. Correspondance scientifique et littéraire. (Recueillie, publiée et précédé d'une notice et d'une introduction par M. De la Roquete). Paris: E. Ducrocq, 1865. 467p. Acréscimo do tradutor.

12 DE LA ROQUETE, M. Notice sur le vie e les travaux de M. Le Baron Alexandre de Humboldt. In: Bulletin de la Societé de Géographie. Quatrième série. Tome dix-neuvième. Janvier-juin, pp. 209-251. Paris: Arthus-Bertrand, 1860. Acréscimo do tradutor.

${ }^{13}$ Mineral vulcânico. (N. T.).
} 
para recompor, com o auxílio dos fenômenos, o conjunto da natureza, mostrando nos grupos isolados destes fenômenos as condições que lhes são comuns, isto é, as grandes leis que regem o mundo; por fim, para ver como - do conhecimento destas leis remontamos ao vínculo da causalidade que reata uns aos outros. Para chegar a compreender o plano do mundo e a ordem da natureza, devemos começar por generalizar os fatos particulares, por procurar naquelas condições as mudanças, as alterações físicas se manifestando e se reproduzindo. Conduzimos assim a uma contemplação refletida dos materiais fornecidos pela observação, e não a uma idéia de mundo puramente especulativa, a uma monadologia absoluta, independente da experiência. Para algumas partes da ciência, ao menos, é verdade dizer que a descrição física do mundo é explicação do mundo. Em geral, esses dois termos não podem ainda ser considerados como idênticos" (HUMBOLDT, 1851, pp. 08-09) ${ }^{14}$.

14 Cosmos, Introdução do terceiro volume. Consultar - H. Klencke, Alexander von Humboldt, ein biographisches Denkmal, Leipzig, 1851. - K. Bruhns, A. von Humboldt, eine wissenschaftliche Biographie, 3 vol., Leipzig, 1872. - Briefe Alexander's von Humboldt an seinen Bruder Wilhelm, Stuttgart, 1880.

(Alenxander von Humboldt, um memorial biográfico; A. von Humboldt, uma biografia científica; Cartas de Alexander von Humboldt ao seu irmão Wilhelm - respectivamente). Tradução livre nossa.

- A referência da paginação aqui citada no último parágrafo (HUMBOLDT, 1851, p. 06-07) fora extraído de uma edição de 1851, na qual a consultamos. HUMBOLDT, Alexandre de. Cosmos: essai d'une description physique du monde. (Traduction de M. H. Faye). Troisième partie (Vol. 3). Milan: Charles Turati, 1851. 436p. Acréscimo do tradutor. 